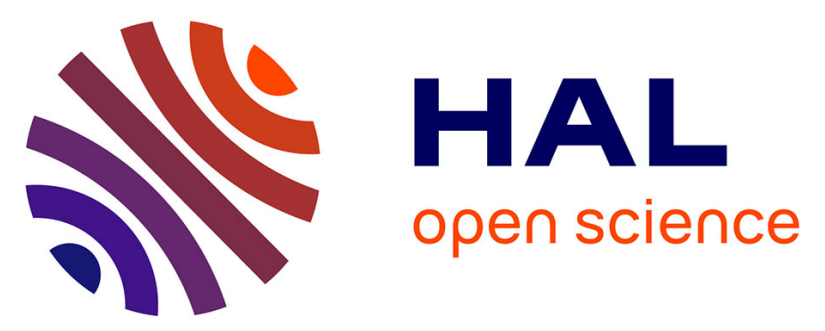

\title{
Should We Disable the Comment Function on Social Media? The Impact of Negative eWOM on Consumers' Trust in Fashion Presentations
}

\author{
Julian Bühler, Matthias Murawski, Markus Bick
}

\section{To cite this version:}

Julian Bühler, Matthias Murawski, Markus Bick. Should We Disable the Comment Function on Social Media? The Impact of Negative eWOM on Consumers' Trust in Fashion Presentations. 16th Conference on e-Business, e-Services and e-Society (I3E), Nov 2017, Delhi, India. pp.325-338, 10.1007/9783-319-68557-1_29. hal-01768511

HAL Id: hal-01768511

https://hal.inria.fr/hal-01768511

Submitted on 17 Apr 2018

HAL is a multi-disciplinary open access archive for the deposit and dissemination of scientific research documents, whether they are published or not. The documents may come from teaching and research institutions in France or abroad, or from public or private research centers.
L'archive ouverte pluridisciplinaire HAL, est destinée au dépôt et à la diffusion de documents scientifiques de niveau recherche, publiés ou non, émanant des établissements d'enseignement et de recherche français ou étrangers, des laboratoires publics ou privés.

\section{(c)(1)}

Distributed under a Creative Commons Attribution| 4.0 International License 


\title{
Should we disable the comment function on social media? The impact of negative eWOM on consumers' trust in fashion presentations
}

\author{
Julian Bühler, Matthias Murawski, and Markus Bick \\ ESCP Europe Business School Berlin, Berlin, Germany \\ $\{$ jbuehler, mmurawski, mbick\} descpeurope.eu
}

\begin{abstract}
Electronic word-of-mouth (eWOM) has attracted a great deal of attention in both academia and practice in recent years. Our empirical study investigates the relation of negative comments and consumers' trust in fashion presentations focusing on clothing. It is a product category characterized by a lot of online conversation and opinion sharing, but is surprisingly underresearched regarding eWOM. We calculate a multiple regression model moderated by consumers' social media experience to identify the impact of a dichotomous eWOM stimulus. We find that negative comments referring to a fashion presentation cause a significant decrease of trust. However, the more experienced a user is in dealing with social media services such as Facebook or YouTube, the weaker this effect will get. These findings contribute to the existing academic discourse about the impact of negative eWOM.
\end{abstract}

Keywords: Clothing, Moderated Regression, Negative eWOM, Social Media, Trust, Valence.

\section{Introduction}

In September 2014, the famous gamer and YouTuber Felix "PewDiePie" Kjellberg, who had more than 30 million subscribers at this time, disabled the comment function for his videos as he was not satisfied with the content of most of the comments [1]. This led to an intense debate about online comments in general. In this study, we transfer this debate to a business context.

Today, the Internet is not just a mere collection of websites; it is also a platform for interactive exchange of opinions and experiences. Countless anonymous senders and receivers can communicate with one another and spread their messages [2]. Enabled by the Internet, phenomena such as the megaphone effect have emerged, meaning that ordinary customers can reach a mass audience [3], e.g. through online comments. Research shows that the majority of consumers tend to rely more on the messages of people who are similar to themselves, e.g., $61 \%$ of consumers refer to blogs or other social platforms for gathering feedback on products or services before buying [4]. In addition, there is empirical evidence validating the meaning of social media for marketing purposes, leading to an increase in sales [5]. 
Consequently, the topic of electronic Word-of-Mouth (eWOM) becomes increasingly important for any marketing strategy [6] and has attracted remarkable attention within the academic community [7]. Besides marketing, the IS field takes a leading role in research on eWOM [8], dealing with topics such as eWOM credibility [9], trust and satisfaction in e-commerce [10], or trust-building web strategies [11].

In this study, we place the focus on three aspects of eWOM. First, we consider negative consumer reviews as a specific field of valence research [12]. Generally, research on the impact of valence shows differing results, which motivates a need for further investigation [13]. More specifically, while most studies deal with positive eWOM, or the comparison of positive and negative eWOM, we investigate the impact of negative eWOM compared to no eWOM at all. This can be considered as a relevant aspect because prominent social media services such as YouTube offer the opportunity to completely disable the comment function on their websites - as "PewDiePie" did. Although studies have started to investigate the impact of negative eWOM [14, 15], further exploration is required [7]. Second, building on an established web trust model [16], we investigate the role of eWOM on consumers' trust in a product presentation. Third, our study deals with a specific product category which is clothing. The topic of eWOM in fashion industry is rather under-researched [17], although social media in general and sharing opinions about clothing and style play a primary role in this field [18]. Therefore, the main objective of our paper is to examine the impact of negative eWOM on consumers' trust in a clothing product presentation. For this purpose, we have designed an online questionnaire yielding a sample of 101 participants. In an experimental setting, a dichotomous eWOM stimulus is varied and we investigate its impact on a social media display of clothing. We calculate the corresponding multiple regression model and include social media experience as a moderating factor in our statistical evaluation.

The remainder of this paper is organized as follows: section 2 contains an overview of the current state of research on eWOM and trust in general before focusing on the meaning of eWOM for fashion products. In section 3 we describe our research approach and in section 4 we present our results. They are discussed and linked to existing research in section 5, before we end with concluding remarks in section 6 .

\section{Theoretical Foundation}

\subsection{Introduction to eWOM}

The emergence of eWOM is based on the rise of e-commerce and social media. First definitions of eWOM aimed at the distinction to 'traditional' WOM, e.g. regarding size of network, speed of diffusion, or privacy [7]. According to Trenz and Berger [19], the most widespread definition of eWOM is the following one by HennigThurau et al::

eWOM is any positive or negative statement made by potential, actual, or former customers about a product or company, which is made available to a multitude of people and institutions via the Internet. [20] 
However, while emphasizing positive or negative statements, this definition does not consider neutral statements. Another limitation is that brands are not included. Thus, we follow a recent definition of eWOM proposed by Ismagilova et al. [7] which underlines that eWOM is not a static process and specifies content and sources of recommendations:

eWOM is the dynamic and ongoing information exchange process between potential, actual, or former consumers regarding a product, service, brand, or company, which is available to a multitude of people and institutions via the Internet. [7]

From a technological perspective, eWOM is based on social media that is predominantly developed for private and non-commercial communication. Although senders and receivers usually do not have any commercial intentions, their messages often contain product names, or brands [18]. Firms aim to derive valuable insights from these crowds' messages and use them to design marketing campaigns or develop products, which indicates the link between eWOM and crowd-sourcing [21]. Generally, scholars have investigated different facets of eWOM, e.g., motivation to engage in eWOM [18, 20], antecedents of using online reviews [22], or the value of eWOM [23].

Our study contributes to another research stream of eWOM which is valence. Valence refers to the positive or negative rating assigned by consumers when they evaluate a product or service [12] and is found to be a significant factor for perception of a product or brand attitude [24]. In terms of theoretical foundation, the optimal arousal theory combined with the two-sided appeal [25] provide the logical reasoning for this. The two-sided appeal describes that a company allows both positive and negative reviews as this indicates a higher credibility [13]. The optimal arousal theory assumes that each person has a unique 'optimal' arousal level and when the arousal level drops below this optimal level, stimulation is required. Individuals prefer stimuli that are moderately novel over stimuli that offer too much or too little novelty [13]. Due to the two-sided appeal, the perceived novelty can be increased moderately as positive and negative reviews are allowed, thus leading to a heightened chance of consumers attention [25].

Some studies find that negative eWOM has a stronger impact on all phases of the consumer decision making process as well as on consumers' attitude of brands than positive eWOM $[26,27]$. This asymmetry can be explained by the 'negativity effect' [28] which means that 'negative product attributes are believed to be more characteristic of a poor quality product, than positive attributes are for a high quality product' [26]. In other words, negative framing seems to be more effective than positive framing [29]. This is in line with the core idea of prospect theory which says that the value function is generally steeper for losses than for gains [30].

However, other studies dealing with the impact of valence draw differing conclusions and find that positive eWOM is more persuasive than negative eWOM [31] or that eWOM valence does not affect product sales at all [24]. These contrasting results indicate a clear research gap regarding valence in general and negative eWOM in particular [7]. Our study addresses this gap by investigating the impact of negative eWOM on consumers' trust in the respective product presentation. 


\section{2 eWOM and trust}

We define trust as 'an actor's expectation of the other party's competence and goodwill' [32], because this definition includes both technical capabilities and skills ('competence') and the more abstract goodwill implying moral responsibility and positive intentions towards the other. Generally, prior research shows strong relations between eWOM, trust, and purchase intentions [8] and it is proven that eWOM has an impact on consumers' trust in a firm and its products [33]. In the context of eWOM and trust, the trust typology by McKnight et al. [16] is often adopted [8]. As illustrated in Fig. 1, trust in a web context is a complex system. In line with our research goal to investigate consumers' trust in a product presentation, we place the focus on trusting beliefs (grey box in Fig. 1). Trusting beliefs is defined as 'the confident truster perception that the trustee - in this context, a specific Web-based vendor-has attributes that are beneficial to the truster.' [16]. Trusting beliefs can be divided in three subgroups: 'competence (ability of the trustee to do what the truster needs), benevolence (trustee caring and motivation to act in the truster's interests), and integrity (trustee honesty and promise keeping)' [16]. Although all three beliefs seem to play a role for our research, the most important one is probably integrity since consumers have a strong need for an 'honest' product presentation and that 'promises' made in the presentation are kept by the company.

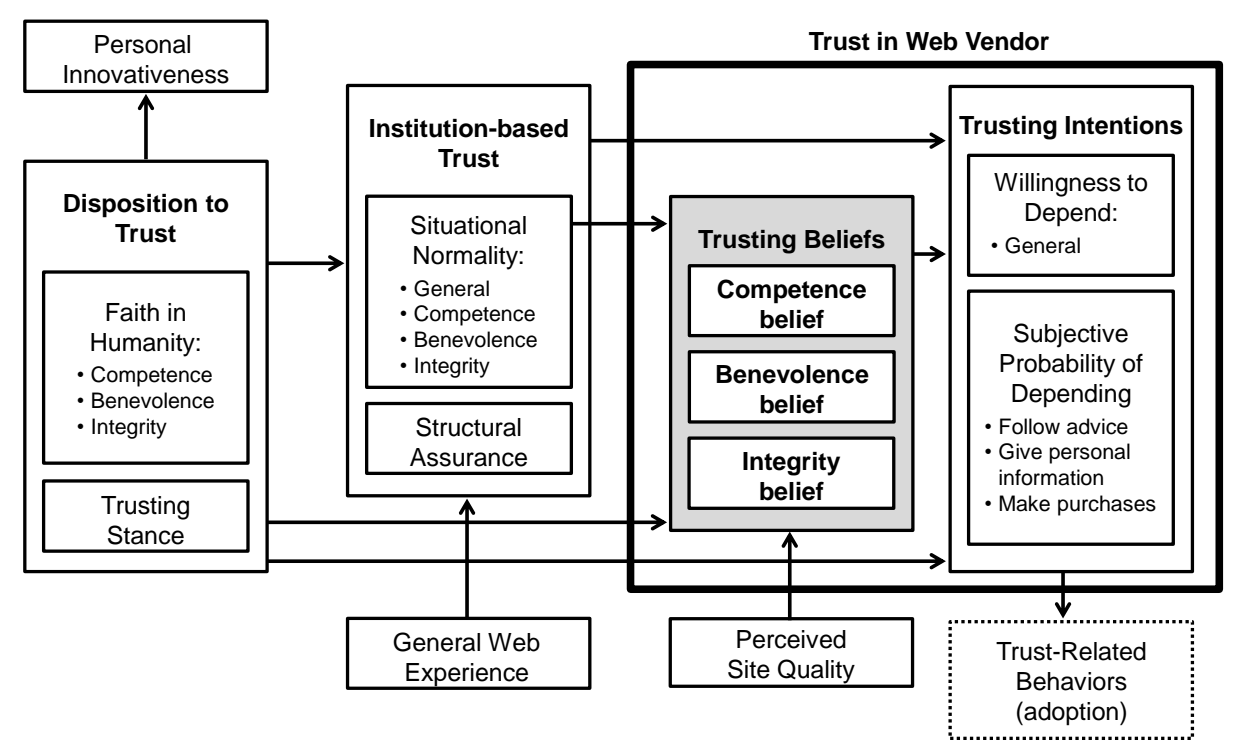

Fig. 1. Web trust model by McKnight et al. (2002, p. 341) [16]

When it comes to trust in eWOM context, most studies compare the impact of positive and negative comments [34] and consider different product types [35]. In contrast to the mostly used approach of comparing positive and negative reviews, we conduct a comparison of negative eWOM with the case of no comments at all, meaning neither positive nor negative nor neutral eWOM. This approach is similar to studies that 
examine the influence of complaint websites on trust in a firm or product [36, 37]. Their findings indicate that negative eWOM reduces trust [8]. However, they do not provide theoretical reasoning. Before formulating hypotheses, we describe the product type we consider in our study in section 2.3 .

\section{3 eWOM in fashion industry}

Individuals often define themselves and others in terms of their possessions, which serve as key symbols for personal qualities and interests. Fashion, or more specifically clothing, is seen as such a possession [38]. In addition, fashion acts as a powerful social symbol, which is used to create and communicate personal as well as group identities [39]. Wolny and Mueller [18] emphasize the network effect associated with fashion: '[fashion] trends are co-created by consumers who not only perpetuate but also adapt them along the way. Such network effects mean that when a trend is adopted successfully by a number of people, it impacts the perceived value of the product for another user, in a positive or negative way, depending on the reference point.' [18]. That means, products that one owes determine how a person is perceived by others [40], which naturally has implications for peer-to-peer communication about fashion [18].

Fashion in general can be assigned to high-involvement products, which means 'either expensive, rarely bought, linked to personal identity, or carry high risks (social or otherwise)' [18]. Research indicates that such high-involvement products attract a lot of online conversation between customers [41]. This might be related to the complexity in determining the value of fashion, leading to increased information sharing in social media with the aim of receiving feedback regarding one`s fashion choices [42].

Kulmala et al. [17] illustrate the process and elements in creating eWOM in fashion blogs. They distinguish between organic and amplified eWOM. Organic (or endogenous) eWOM means that a person wants to tell others about an experience, for instance with a product, and does not entail any direct intervention from the firm. In contrast, amplified (or exogenous) eWOM occurs when a firm encourages others (e.g., bloggers) to speak about their product or tries to actively influence customer-tocustomer interaction [43]. Kulmala et al. [17] find that amplified eWOM content in consumer fashion blogs resembles organic content. The main topics discussed in organic eWOM include personal style, brands, and designers and retailers, while amplified topics are products received by the blogger, brands, and designers and retailers [17]. Although amplified eWOM seems to increase in relevance, we consider organic eWOM in our study.

Apart from studies dealing with eWOM in retailing in general [14], consumers' motivation to engage in fashion-related eWOM [18], and different types of eWOM in fashion blogs [17], research on eWOM with a focus on fashion or clothing is scarce [17]. With respect to the high level of personal involvement and emotions related to fashion in general and clothing in particular [18,41], we believe it is worth investigating the impact of negative comments on consumers' trust (i.e., trusting beliefs, see Fig. 1) in the presentation of clothing. This is in line with current conceptual research on the impact of eWOM on trust which is grounded in research on complaint websites 
$[36,37]$. For instance, See-To and Ho [8] formulate the proposition 'negative eWOM will weaken the user's trusting belief on the firm'. Based on these thoughts, we develop the following hypotheses:

H1 Consumers trust a social media presentation of clothing less if it is accompanied by negative eWOM compared to the case of absence of any eWOM.

H2 The impact of negative eWOM on trust in a social media presentation of clothing is moderated by the level of social media experience.

$\mathrm{H} 1$ clearly reflects the main objective of our study. Although considering a negative one-sided appeal, we posit that consumers trust a product presentation less if negative comments exist compared to a presentation that is free of any eWOM influence (e.g., because of disabled comment functions). Furthermore, we believe that the consumers' social media experience moderates the relation described in H1. This moderating role of experience follows the approach of established models in the field of behavioral research and technology acceptance research, such as the Unified theory of Acceptance and Use of Technology (UTAUT) [44].

\section{$3 \quad$ Research approach}

Based on the two hypotheses we derived from the literature review, we can create our research model which will be validated in the empirical section (Fig. 2).

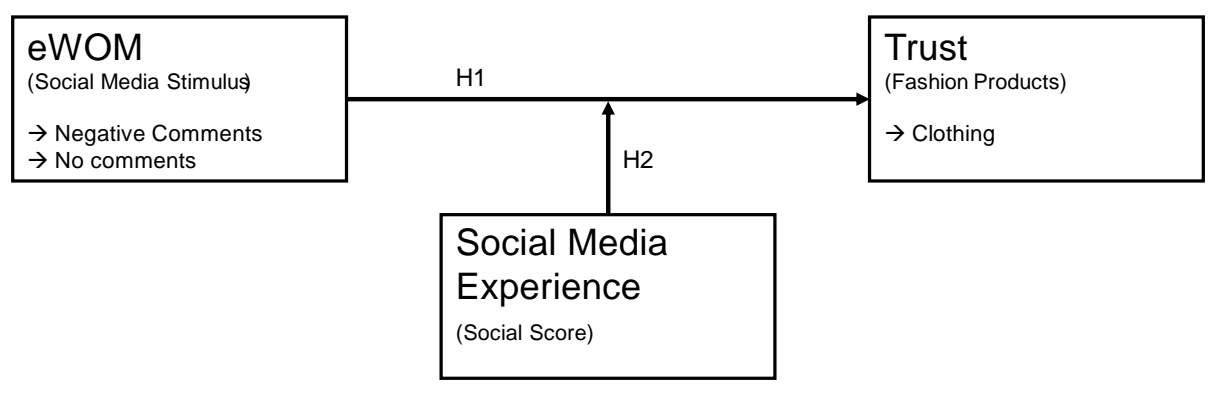

Fig. 2. Research Model on eWOM

For the empirical validation of the model, we developed a questionnaire which meets the characteristics previously identified in the literature review. The first two sections contain demographic questions, i.e., age, gender, and questions addressing participants' general social media behavior, i.e., frequently used social media services and important topics on corresponding social media platforms.

To test our hypotheses empirically, it was also necessary to select a suitable survey setting in order to measure differences regarding eWOM, specifically between its two alternative parameters negative comments compared to no comments. Experimental designs generally vary a factor called stimulus and measure its impact on a dependent variable [45]. We decided to use such an experimental approach as both comment parameters form the external eWOM stimulus which serves as an independent varia- 
ble, the social media stimulus. In our research model, it impacts the way social media users perceive a product presentation online and, consequently, their trust in a product. As an instrument to measure the different impacts, we capitalized on the concept of randomization [46, 47]. At runtime, participants were allocated randomly to either group A or group B and were presented with two alternative displays, each representing the no comments (group A) or negative comments (group B) stimulus.

Thus, participants of both groups had to answer the same questions in the first two sections of the questionnaire, but received a different stimulus in the last section. As the focus of this study lies on fashion, especially on clothing, we varied a social network display that shows a young couple wearing the same type of a white $t$-shirt, a green jacket, and brown trousers. Group A could only see a picture of this couple whereas Group B was additionally confronted with negative comments on the style. Both groups were then asked to rate both the style and their level of trust on scales ranging from 'not stylish/not trustworthy' to 'really stylish/trustworthy'.

Regarding the target group, we decided to mainly ask younger adult users (18 years or older) including Millennials, but did not technically limit it to this cluster. Millennials are a suitable core target group because they can be characterized as digital natives who are often familiar with all kinds of social media services such as Facebook or Twitter [48]. Thus, they very likely have a large social media affinity and have already experienced situations where eWOM has potentially influenced their use behavior. Since we investigated social media as a stimulus as visualized in the research model, we could focus on the main social media services for acquisition purposes without causing a sample bias. The survey link was distributed through Facebook and Twitter - two of the largest social media services [49] — and additionally cross promoted through various other online (e.g., e-mail) and offline channels (notice boards). Participants took part in the survey exclusively online so that we could guarantee an accurate randomization and an identical digital presentation of both alternative displays. It was implemented with the tool Limesurvey and both the acquisition as well as the final sampling took place between November 2015 and January 2016 after initial pretests with university students.

For the analysis, we use version 23 of the statistics software IBM SPSS Statistics (SPSS). The first two sections of the survey contain dichotomous and multiple-choice questions whereas for the randomization, 5-Point Likert scales are used to measure style and trust. This scaling allows us to calculate several t-tests and a regression as we can assume equidistant items and, consequently, metrical scale levels [50]. T-tests can be used in our study to compare average means between the two stimulus groups, and we use them to make sure that our independent samples are not statistically different regarding the factors age and social media affinity. This is necessary to avoid unintentional impacts on the model caused by these factors. To predict the influence of eWOM on trust in our clothing displays, we calculate a multiple regression with and without moderation. Both models can be compared to shed light on the moderating effect of social media experience [51]. 


\section{$4 \quad$ Results}

\subsection{Descriptive results}

After a period of seven weeks, we finally received 135 survey responses of which 34 had to be rejected. Plausibility checks reveal that these responses are not filled out completely, fail to meet necessary levels of accuracy such as response times or age, or indicate response bias issues. Thus, the final sample size included in the model analysis is $n=101$ survey participants. The initial descriptive results are presented in Table 1 and reveal a similar distribution in terms of gender and age. The intended target group of young adults and Millennials could be addressed with the questionnaire according to the average age.

Table 1. Descriptive sample results

\begin{tabular}{|c|c|l|c|c|c|}
\hline \multicolumn{4}{|c|}{ Gender } & \multicolumn{3}{c|}{ Age } \\
Group & N & Male & Female & Mean $^{\text {a }}$ & SD \\
\hline A & 52 & 24 & 28 & 26.56 & 5.82 \\
\hline B & 49 & 21 & 28 & 25.04 & 4.32 \\
\hline
\end{tabular}

a) p>0.05, t-test not statistically significant between groups $A$ and $B$

We controlled the randomization process by applying a t-test for age. Results (sig. 2-tailed: .142) indicate no statistically significant differences between both groups. Taking both t-test results and the similar gender distribution, we can assume that no bias interfered with the randomization process and both groups are rather homogenous. Thus, potential differences can be linked to the variation of the stimulus rather than demographic effects.

\subsection{Social Score}

Because we investigate the impact of a social media stimulus in our model, we first ask the respondents to disclose their general social media usage. For the most relevant services participants can state whether they use them or not. Like in the ALEXA ranking, Facebook is the favorite service [49], and nearly all participants in the sample use it. A comparably large gap following YouTube on second place marks the cut between two dominant services on the one hand, and a portfolio of other services used less frequently on the other hand. Surprisingly, Instagram was ahead of Twitter in contrast to the order in the ALEXA ranking. The results are visualized in Fig. 3. 


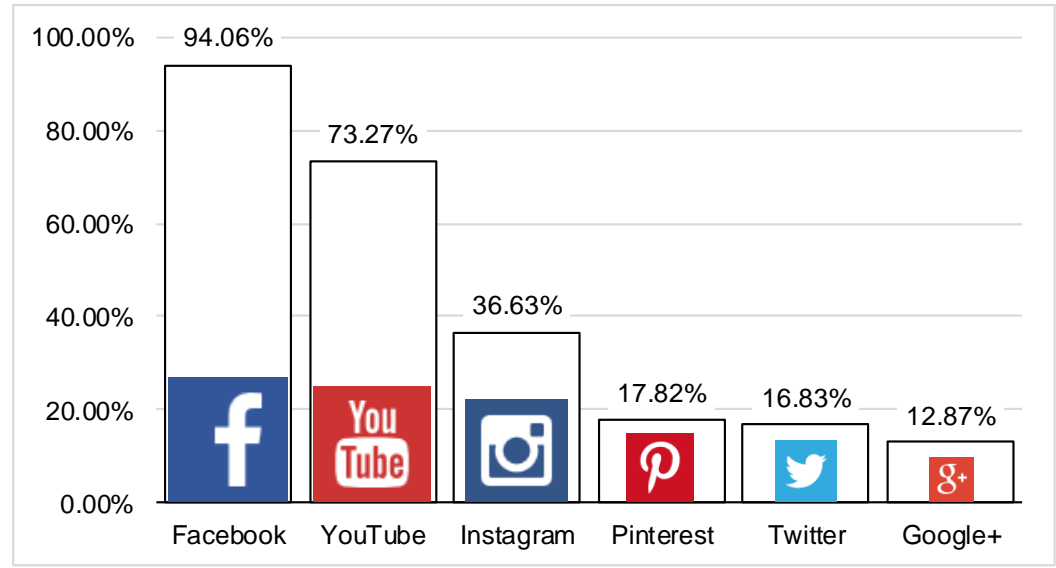

Fig. 3. Social Media Usage

Based on these results, we calculate a social score which we use as the moderating variable in our model. It represents the social media experience of a user and is the aggregated number of services used by a participant. A majority of participants in the sample regularly use two or three different services, mostly including Facebook and YouTube whereas $17.8 \%$ are less experienced (score: 1 ) or very experienced (score: 4 or 5). On average, participants reach a score of 2.51 (SD: 1.1) and t-test results again reveal no significant differences between both groups.

\subsection{Multiple regression and moderation results}

We measure eWOM through a social media stimulus which is dichotomous. Thus, this variable is dummy-coded as $0 / 1$ with 0 representing no comments and 1 representing negative comments. Trust in the display of a couple wearing a specific dress is measured on a 5-point Likert scale and for the moderating effect of the social media experience we use the social score. The social score forms an interaction term with the social media stimulus by multiplication of both variables. This results in two different models, one model without moderation (model 1) and another one with the interaction effect (model 2), which can be compared to identify a moderating effect $[50,52]$.

Overall results indicate a significant moderating effect as the $\mathrm{R}^{2}$ changed increased by $4.8 \%$ (Sig. Change: .027**) in the second model. The interaction effect causes the second regression model to be statistically significant in contrast to model 1 (Table 2). 
Table 2. Significance of regression models ${ }^{\text {a }}$

\begin{tabular}{|c|c|c|c|c|l|}
\hline Model & Sum of Squares & df & \multicolumn{1}{l|}{ Mean Square } & \multicolumn{1}{l|}{ F } & Sig. \\
\hline 1 & 4.130 & 2 & 2.065 & 1.807 & $.170^{\mathrm{b}}$ \\
\hline 2 & 9.674 & 3 & 3.225 & 2.938 & $.037^{\mathrm{c}} * *$ \\
\hline
\end{tabular}

a. Dependent Variable: Trust in the display

b. Predictors: (Constant), Social Score (SC), Social Media Stimuli (ST)

c. Predictors: (Constant), SC, ST, SCxST

$* * \mathrm{p}<0.05$

This moderating effect can be investigated in more detail for the individual predictor variables. In model 1, the social media stimulus representing the eWOM effect is only weakly significant on the $90 \%$ confidence level whereas in the second model, it is highly significant $(\mathrm{p}<0.01)$ as well as the moderator $(\mathrm{p}<0.05)$. The strong negative standardized beta coefficient $(-0.675)$ for the social media stimulus indicates a decrease in trust if negative comments exist. This effect is moderated in such a way that the less experienced a social media user is, the stronger the decrease in results will be (Table 3).

Table 3. Coefficients of the regression models ${ }^{\text {a }}$

\begin{tabular}{|c|c|c|c|c|c|c|}
\hline \multirow[t]{2}{*}{ Mode } & & \multicolumn{2}{|c|}{$\begin{array}{l}\text { Unstandardized } \\
\text { Coefficients }\end{array}$} & \multicolumn{3}{|c|}{$\begin{array}{l}\text { Standardized } \\
\text { Coefficients }\end{array}$} \\
\hline & & B & Std. Error & Beta & $\mathrm{T}$ & Sig. \\
\hline \multirow[t]{3}{*}{1} & (Constant) & 3.541 & .284 & & 12.450 & .000 \\
\hline & ST & -.364 & .213 & -.170 & -1.711 & $.090 *$ \\
\hline & SC & -.078 & .097 & -.080 & -.805 & .423 \\
\hline \multirow[t]{4}{*}{2} & (Constant) & 4.148 & .388 & & 10.691 & .000 \\
\hline & ST & -1.448 & .525 & -.675 & -2.756 & $.007 * * *$ \\
\hline & $\mathrm{SC}$ & -.321 & .144 & -.328 & -2.229 & $.028 * *$ \\
\hline & SCxST & .431 & .192 & .606 & 2.248 & $.027 * *$ \\
\hline
\end{tabular}

a. Dependent Variable: Trust in the display

$* \mathrm{p}<0.1, * * \mathrm{p}<0.05, * * * \mathrm{p}<0.01$

\section{Discussion}

With regard to our two initial hypotheses, we can summarize our findings as follows: $\mathrm{H} 1$ is supported because the level of trust in the presentation of clothing is significantly lower if negative comments are linked to the display. This effect is rather weakly significant, though. $\mathrm{H} 2$ addresses the moderating effect of social media experience and is strongly supported. The moderation is highly significant as the negative influence of negative comments on trust mainly exists for unexperienced users. Fig. 4 visualizes the strong negative slope if no moderation is considered (black line) in contrast to the nearly unchanged moderated (grey) line. This indicates that experi- 
enced social media users are hardly not influenced by negative comments of other users. Thus, eWOM plays a less important role for them. However, users who are not so familiar with the various social media services can be influenced by these negative eWOM stimuli.

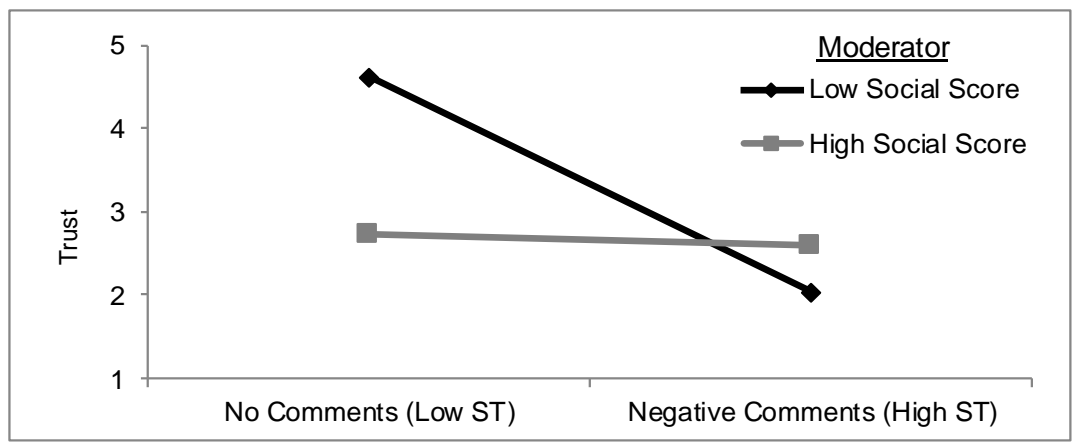

Fig. 4. Moderating effect of social media experience

Our findings support the proposition of See-To and Ho [8] that says negative eWOM will weaken the user's trusting belief on the firm. This might be explained by the fact that clothing is a high-involvement product which is very sensitive to negative comments. Furthermore, our findings seem to fit to optimal arousal theory. People need stimuli to maintain their optimal arousal level and negative stimuli are stronger than the stimuli only based on the product presentation without any eWOM. In addition, this stimulus is lower for more experienced users (H2). At first glance, our findings seem to support the negativity effect. However, the negativity effect focuses explicitly on the comparison between positive and negative eWOM. As we apply a different approach, no final statement on the negativity effect can be made.

\section{Conclusion}

Our study contributes to the topic of negative eWOM while focusing on a rather under-researched product category (clothing). In addition, by empirically investigating trusting beliefs, we contribute to a better understanding of the web trust model of McKnight et al. [16]. Our main finding is that the trust level is significantly lower if there is negative eWOM compared to if there is no eWOM. However, this finding alone is not sufficient to decide on questions such as enabling or disabling comment functions. There are basically two reasons for this. First, we consider negative and no eWOM, but we do not consider positive eWOM. In follow-up studies, our setting could be easily extended to a tripartite combination of positive, negative, and no comments. Consequently, the relatively small sample size of our initial experimental setting would be enlarged to allow accurate generalizations as well. Second, research shows promising results for firms with a sound response strategy on negative eWOM $[7,37]$. Including these aspects in a comprehensive study would potentially lead to more concrete managerial implications. Besides these limitations, it can be concluded 
that negative eWOM should never be underestimated, especially when it concerns sensitive products such as clothing. Ignoring negative eWOM could harm the relationship to customers which might result in decreasing sales. As found in our study presentations within the social media environment are especially vulnerable to negative eWOM. Thus, one practical recommendation for marketers is to disable the comment function if the channel is not administrated regularly, e.g., a channel below a YouTube video, to avoid loss of consumers' trust.

Recent scientific work on eWOM offers a multitude of further research opportunities. One aspect which might be particularly relevant for our study is the quality of comments. It can be shown that the influence of eWOM varies depending on the quality of comments (i.e., high-quality vs. low-quality) [15]. Thus, as we have used the same negative comments in our survey, this distinction would be a valuable advancement of our research approach.

The final remark refers to our introductory example: "PewDiePie" re-activated the comment function for his videos one month after he disabled it.

\section{Acknowledgment}

We are grateful for the support of Mirja Frey throughout the data acquisition stage.

\section{References}

1. Stuart, K.: PewDiePie switches off YouTube comments: 'It's mainly spam', https://www.theguardian.com/technology/2014/sep/03/pewdiepie-switches-off-youtubecomments-its-mainly-spam

2. Hettler, U.: Social Media Marketing. Oldenbourg Wissenschaftsverlag (2012)

3. McQuarrie, E.F., Miller, J., Phillips, B.J.: The Megaphone Effect. Taste and Audience in Fashion Blogging. J Consum Res 40, 136-158 (2013)

4. Cheung, C.M., Lee, M.K.: What drives consumers to spread electronic word of mouth in online consumer-opinion platforms. Decision Support Systems 53, 218-225 (2012)

5. Mikalef, P., Giannakos, M., Pateli, A.: Shopping and Word-of-Mouth Intentions on Social Media. J. theor. appl. electron. commer. res. 8, 5-6 (2013)

6. Eccleston, D., Griseri, L.: How does Web 2.0 stretch traditional influencing patterns? Int. J. Market Res. 50, 591-616 (2008)

7. Ismagilova, E., Dwivedi, Y.K., Slade, E., Williams, M.D.: Electronic Word of Mouth (eWOM) in the Marketing Context. Springer International Publishing, Cham (2017)

8. See-To, E.W., Ho, K.K.: Value co-creation and purchase intention in social network sites. The role of electronic Word-of-Mouth and trust - A theoretical analysis. Computers in Human Behavior 31, 182-189 (2014)

9. Lis, B.: In eWOM We Trust - A Framework of Factors that Determine the eWOM Credibility. Business \& Information Systems Engineering 5, 129-140 (2013)

10. Kim, D.J., Ferrin, D.L., Rao, H.R.: Trust and Satisfaction, Two Stepping Stones for Successful E-Commerce Relationships. A Longitudinal Exploration. Information Systems Research 20, 237-257 (2009)

11. Sia, C.L., Lim, K.H., Leung, K., Lee, M.K.O., Huang, W.W., Benbasat, I.: Web strategies to promote internet shopping. Is cultural-customization needed? MIS Quarterly 33, 491$512(2009)$ 
12. King, R.A., Racherla, P., Bush, V.D.: What We Know and Don't Know About Online Word-of-Mouth. A Review and Synthesis of the Literature. Journal of Interactive Marketing 28, 167-183 (2014)

13. Shaw, V., Coker, B.: Keeping negative Facebook comments leads to more trust in your brand. The 2012 World Congress in Computer Science Engineering and Applied Computing, Las Vegas, NV 2012

14. Davis, A., Khazanchi, Deepak: The Influence of Online Word of Mouth on Product Sales in Retail E-commerce: An Empirical Investigation. Proceedings of the Thirteenth Americas Conference on Information Systems (AMCIS) (2007)

15. Lee, J., Park, D.-H., Han, I.: The effect of negative online consumer reviews on product attitude:. An information processing view. Electronic Commerce Research and Applications 7, 341-352 (2008)

16. McKnight, D.H., Choudhury, V., Kacmar, C.: Developing and Validating Trust Measures for e-Commerce. An Integrative Typology. Information Systems Research 13, 334-359 (2002)

17. Kulmala, M., Mesiranta, N., Tuominen, P.: Organic and amplified eWOM in consumer fashion blogs. Jnl of Fashion Mrkting and Mgt 17, 20-37 (2013)

18. Wolny, J., Mueller, C.: Analysis of fashion consumers' motives to engage in electronic word-of-mouth communication through social media platforms. Journal of Marketing Management 29, 562-583 (2013)

19. Trenz, M., Berger, B.: Analyzing Online Customer Reviews - An Interdisciplinary Literature Review And Research Agenda. Proceedings of the European Conference on Information Systems (2013)

20. Hennig-Thurau, T., Gwinner, K.P., Walsh, G., Gremler, D.D.: Electronic word-of-mouth via consumer-opinion platforms. What motivates consumers to articulate themselves on the Internet? Journal of Interactive Marketing 18, 38-52 (2004)

21. Storbacka, K., Frow, P., Nenonen, S., Payne, A.: Designing Business Models for Value Co-Creation. In: Vargo, S.L., Lusch, R.F., Malhotra, N.K. (eds.) Special Issue. Toward a Better Understanding of the Role of Value in Markets and Marketing, 9, pp. 51-78. Emerald Group Publishing Limited, Bingley (2012)

22. Park, C., Lee, T.M.: Antecedents of Online Reviews' Usage and Purchase Influence. An Empirical Comparison of U.S. and Korean Consumers. Journal of Interactive Marketing 23, 332-340 (2009)

23. Dwyer, P.: Measuring the value of electronic word of mouth and its impact in consumer communities. Journal of Interactive Marketing 21, 63-79 (2007)

24. Davis, A., Khazanchi, D.: An Empirical Study of Online Word of Mouth as a Predictor for Multi-product Category e-Commerce Sales. Electron Markets 18, 130-141 (2008)

25. Crowley, A.E., Hoyer, W.D.: An Integrative Framework for Understanding Two-Sided Persuasion. J Consum Res 20, 561 (1994)

26. van Noort, G., Willemsen, L.M.: Online Damage Control. The Effects of Proactive Versus Reactive Webcare Interventions in Consumer-generated and Brand-generated Platforms. Journal of Interactive Marketing 26, 131-140 (2012)

27. Lee, M., Rodgers, S., Kim, M.: Effects of Valence and Extremity of eWOM on Attitude toward the Brand and Website. Journal of Current Issues \& Research in Advertising 31, 111 (2009)

28. Ahluwalia, R.: How Prevalent Is the Negativity Effect in Consumer Environments? J Consum Res 29, 270-279 (2002)

29. Maheswaran, D., Meyers-Levy, J.: The Influence of Message Framing and Issue Involvement. Journal of Marketing Research 27, 361 (1990) 
30. Kahneman, D., Tversky, A.: Prospect Theory. An Analysis of Decision under Risk. Econometrica 47, 263 (1979)

31. Gershoff, A.D., Mukherjee, A., Mukhopadhyay, A.: Consumer Acceptance of Online Agent Advice. Extremity and Positivity Effects. Journal of Consumer Psychology (2003)

32. Blomqvist, K.: The many faces of trust. Scandinavian Journal of Management 13, 271-286 (1997)

33. Dellarocas, C.: The Digitization of Word of Mouth. Promise and Challenges of Online Feedback Mechanisms. Management Science 49, 1407-1424 (2003)

34. Pan, L.-Y., Chiou, J.-S.: How Much Can You Trust Online Information? Cues for Perceived Trustworthiness of Consumer-generated Online Information. Journal of Interactive Marketing 25, 67-74 (2011)

35. Sen, S., Lerman, D.: Why are you telling me this? An examination into negative consumer reviews on the Web. Journal of Interactive Marketing 21, 76-94 (2007)

36. Bailey, A.A.: Thiscompanysucks.com. The use of the Internet in negative consumer-toconsumer articulations. Journal of Marketing Communications 10, 169-182 (2004)

37. Lee, Y.L., Song, S.: An empirical investigation of electronic word-of-mouth. Informational motive and corporate response strategy. Computers in Human Behavior 26, 1073-1080 (2010)

38. O'Cass, A.: Fashion clothing consumption. Antecedents and consequences of fashion clothing involvement. European Journal of Marketing 38, 869-882 (2004)

39. Ahuvia, A.C.: Beyond the Extended Self. Loved Objects and Consumers' Identity Narratives. J Consum Res 32, 171-184 (2005)

40. Kamineni, R.: Influence of materialism, gender and nationality on consumer brand perceptions. J Target Meas Anal Mark 14, 25-32 (2005)

41. Gu, B., Park, J., Konana, P.: The Impact of External Word-of-Mouth Sources on Retailer Sales of High-Involvement Products. Information Systems Research 23, 182-196 (2012)

42. Lin, T.M., Lu, K., Wu, J.: The effects of visual information in eWOM communication. Jnl of Res in Interact Mrkting 6, 7-26 (2012)

43. Godes, D., Mayzlin, D.: Firm-Created Word-of-Mouth Communication. Evidence from a Field Test. Marketing Science 28, 721-739 (2009)

44. Venkatesh, V., Morris, M.G., Davis, G.B., Davis, F.D.: User Acceptance of Information Technology. Toward a Unified View. MIS Quarterly 27, 425-478 (2003)

45. Keppel, G., Wickens, T.D.: Design and analysis. A researcher's handbook. Pearson/Prentice Hall, Upper Saddle River, N.J. (2004)

46. Kirk, R.E.: Experimental Design. In: Handbook of Psychology. John Wiley \& Sons, Inc (2003)

47. Kirk, R.E.: Experimental Design: Procedures for the Behavioral Sciences. Sage Publications, Thousand Oaks (2012)

48. Statista Inc.: Internet usage of Millennials in the United States, https://www.statista.com/study/19343/millennials-in-the-us-internet-und-online-shopping-statista-dossier

49. Alexa Internet, I.: The top 500 sites on the web, http://www.alexa.com/topsites

50. Hair, J.F., Black, W.C., Babin, B.J., Anderson, R.E.: Multivariate data analysis. Prentice Hall, Upper Saddle River, NJ (2014, 2010)

51. Jaccard, J., Turrisi, R.: Interaction effects in multiple regression. Sage, Thousand Oaks, Calif. (2009)

52. Hayes, A.F.: Introduction to Mediation, Moderation, and Conditional Process Analysis. Guilford Publications, New York (2013). 